\title{
DEEP FLOW TECHNIQUE (DFT) HIDROPONIK MENGGUNAKAN MEDIA NUTRISI LIMBAH CAIR TAHU DAN KAYU APU (PISTIA STRATIOTES L) UNTUK PENINGKATAN PRODUKTIVITAS TANAMAN
}

\author{
1 Maria Yustiningsih, ${ }^{2}$ Yolanda Getrudis Naisumu, ${ }^{3}$ Agustina Berek \\ 1,3 Program Studi Pendidikan Biologi, Fakultas Ilmu Pendidikan \\ 2 Program Studi Biologi, Fakultas \\ Pertanian Universitas Timor \\ Email:yustiningsih@gmail.com
}

Citasi: Yustiningsihi, M., Naisumu, Y. G., \& Berek, A. (2019). Deep Flow Technique (Dft) Hidroponik Menggunakan Media Nutrisi Limbah Cair Tahu Dan Kayu Apu (Pistia Stratiotes L) Untuk Peningkatan Produktivitas Tanaman. Mangifera Edu volume 3 (2): 110-121.

\begin{abstract}
ABSTRAK
Limbah tahu merupakan salah satu jenis limbah yang mengandung bahan organik yang tinggi, namun sering dibuang ke lingkungan tanpa melalui pengolahan. Metode hidroponik Deep Flow Technique (DFT) merupakan metode tanam tanpa menggunakan media tanah tetapi meletakkan akar tanaman pada larutan nutrisi pada kedalaman 4-6 cm pada sirkulasi nutrisi terus menerus. Metode penelitian dengan menggunakan metode kuantitatif, dan desain penelitian dilakukan menggunakan rancangan acak Lengkap (RAL) dengan membandingkan tiga populasi tanaman selada (Lactuna sativa L) yang ditumbuhkan pada 3 (tiga) perlakuan yang berbeda yaitu pertumbuhan tanaman pada media nutrisi hidroponik $A B$ mix (A1), pertumbuhan tanaman pada media nutrisi limbah tahu (A2) dan pertumbuhan tanaman pada media nutrisi limbah tahu dan kayu apu (Pistia stratiotes L) atau A3. Hasil penelitian menunjukkan bahwa ratio EM4 dan limbah tahu yang optimal digunakan untuk media hidroponik adalah ratio 1 :5 karena mempunyai suhu $27^{0} \mathrm{C}, \mathrm{pH}$ 7,6 kadar BOD 412,12 mg/L, kadar COD $913 \mathrm{mg} / \mathrm{L}$ dan TSS $200 \mathrm{mg} / \mathrm{l}$; atau paling mendekati standar baku mutu limbah cair menurut Permen LH NO 5 Tahun 2014. Hasil pertumbuhan tanaman selada (Lactuna sativa L) menunjukkan bahwa pertumbuhan tertinggi adalah pada perlakuan menggunakan nutrisi AB mix (Al) yang mempunyai rata - rata ukuran tanaman paling tinggi 15,14 cm, jumlah daun paling banyak 11,7 dan biomassa paling besar 20,96 gr. Uji lanjutan menggunakan DMRT juga menunjukkan bahwa antar perlakuan terdapat beda nyata. Berdasarkan hasil penelitian dapat disimpulkan bahwa pengolahan limbah tahu menggunakan EM4 mampu mengurangi kadar polutan walaupun masih dibawah standar baku mutu. Limbah tahu dapat digunakan sebagai media nutrisi hidroponik meskipun dengan pertumbuhan yang lebih rendah.
\end{abstract}

Kata kunci : EM4, DFT, Hidroponik, Limbah Tahu, Media, Nutrisi, Ratio

\section{PENDAHULUAN}

Kapubaten Timor Tengah Utara (TTU) terletak di propinsi Nusa Tenggara Timur (NTT) merupakan daerah dengan produktitas tanaman hortikultura dan sayuran yang rendah. Salah satu penyebabnya adalah keterbatasan sumber air karena rata - rata 
intensitas musim hujan yang rendah. Data BMKG menunjukkan bahwa rerata jumlah hari hujan di TTU berkisar 1.411,85 mm per tahun dengan rata - rata hari hujan berkisar 77,58 hari. Masyarakat yang ingin menaman sayuran harus melakukan penyiraman secara rutin dari sumber air terdekat agar dapat menghasilkan tanaman yang layak panen. Oleh karena itu diperlukan metode untuk meningkatkan produktivitas tanaman dan sayuran selain menggunakan media tanah dan penyiraman menggunakan air bersih. Salah satu metode penanaman yang dapat digunakan adalah metode hidroponik

Metode hidroponik adalah salah satu metode tanam tanpa menggunakan media tanah namun menggunakan larutan nutrisi sebagai sumber makanan bagi tanaman dan substrat sebagai media pendukung atau penopang tanaman (Rosliani dan Sumarni, 2005). Salah satu metode hidroponik yang banyak digunakan adalah sistem Deep Flow Technique atau DFT yaitu meletakkan akar tanaman pada lapisan air yang dalam dengan kedalaman lapisan berkisar antara 4-6 cm. Keunggulan metode hidroponik selain tidak memerlukan tanah adalah larutan nutrisi dapat disubtitusi dengan larutan yang lain sejauh kandungan organik di dalamnya mencukupi untuk pertumbuhan tanaman (Rosliani dan Sumarni, 2005). Dengan adanya keunggulan ini maka di beberapa daerah di Indonesia hidroponik mulai dikembangkan dengan menggunakan media dan memanfaatkan larutan nutrisi alternatif selain menggunakan air bersih.

Limbah tahu merupakan salah satu jenis limbah yang mengandung bahan organik yang tinggi (Agung dan Winata, 2012). Menurut Hakim (1986), limbah cair tahu merupakan limbah organik yang mudah diuraikan oleh mikroorganisme secara alamiah. Berdasarkan sifat ini maka pengolahan limbah tahu banyak memanfaatkan proses biologis dengan memanfaatkan berbagai jenis mikroorganisme agar senyawa organik turunan yang dihasilkan dapat didegradasi. Salah satu contoh mikroorganisme pendegradasi senyawa organik dapat ditemukan pada efektive mikroorganisme atau EM4.

Efektive mikroorganisme atau EM4 adalah konsorsium dari berbagai jenis mikroorganisme antara lain bakteri asam laktat Lumbricus sp, bakteri fotosintetik, Actinomycetes, Streptomyces $s p$ dan Ragi. EM4 dapat meningkatkan fermentasi limbah dan sampah organik, meningkatkan ketersediaan unsur hara untuk tanaman, serta menekan aktivitas serangga, hama dan mikroorganisme patogen (Djuarnani, et al, 2005). Menurut Suharjito (2005) dan Rizky (2013) EM4 dapat menurunkan kadar BOD dan COD limbah tahu sebesar $35 \%$, sedangkan Soetrisno et al (2014) menunjukkan bahwa limbah tahu dapat digunakan sebagai alternatif nutrisi pada metode hidroponik tanaman sawi, namun perlu dilakukan secara seksama mengingat masih tersisanya kandungan polutan 
organik yang dapat menempel pada tanaman. Salah satu metode yang dapat digunakan untuk menyerap sisa polutan adalah dengan menggunakan tanaman Pistia stratiotes L. Penelitian bertujuan untuk (1) mendapatkan ratio limbah tahu dan EM4 yang optimal untuk digunakan sebagai nutrisi media hidroponik (2) mengidentifikasi adanya potensi peningkatan produktivitas tanaman menggunakan media nutrisi limbah cair tahu menggunakan metode hidroponik DFT (3) mengidentifikasi perubahan kualitas fisik dan kimia limbah cair hasil fermentasi menggunakan EM4 dan kayu apu yang digunakan pada media hidroponik.

\section{METODE PENELITIAN}

Metode penelitian dengan menggunakan metode kuantitatif, dan desain penelitian dilakukan menggunakan rancangan acak Lengkap (RAL) dengan membandingkan tiga populasi tanaman selada (Lactuna sativa $\mathrm{L}$ ) yang ditumbuhkan pada 3 (tiga) perlakuan yang berbeda yaitu pertumbuhan tanaman pada media nutrisi hidroponik AB mix (A1), pertumbuhan tanaman pada media nutrisi limbah tahu (A2) dan pertumbuhan tanaman pada media nutrisi limbah tahu dan kayu apu (Pistia stratiotes L) atau A3. Jumlah populasi tiap perlakuan adalah 39 tanaman dan 10 tanaman menjadi sampel. Prosedur penelitian melalui 4 tahap yaitu : Aktivasi EM4, Optimasi EM4, Pembuatan Kerangka dan Kontruksi Hidroponik DFT, serta penanaman dan pengamatan parameter. Desain DFT seperti tampak pada gambar 1. Parameter yang diamati adalah kualitas air limbah (BOD,COD,TSS, $\mathrm{pH}$,temperatur, $\mathrm{pH}$ ) dan parameter pertumbuhan dan produktivitas tanaman (tinggi tanaman, jumlah daun, panjang akar, panjang tunas dan biomassa tanaman). Data yang dihasilkan dianalisis secara statistik menggunakan metode analisis variansi (ANOVA) dengan menggunakan program SPSS. Uji lanjut dilakukan dengan menggunakan rentang kepercayaan $95 \%(\mathrm{p} \leq 0,05)$. 


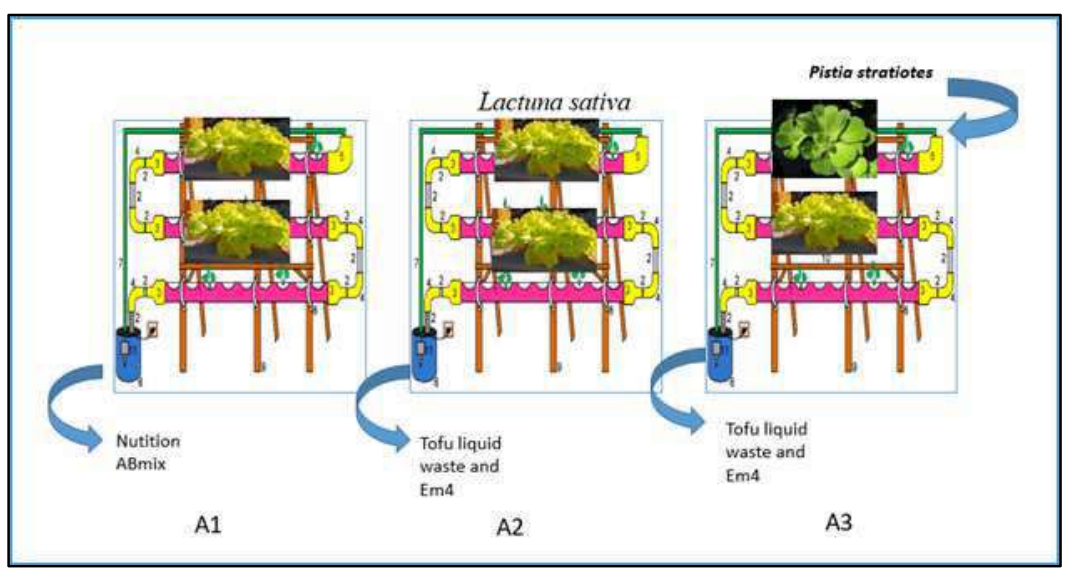

\section{Gambar 1. Rancangan konstruksi hidroponik DFT pada 3 jenis perlakuan A1,A2 dan A3}

\section{HASIL DAN PEMBAHASAN}

Penelitian diawali dengan pengenceran atau aktivasi EM4 menggunakan akuades dengan perbandingan 1:20 (EM4 1 liter dan akuades 20 liter ) kemudian didiamkan selama 7 hari pada suhu ruang menurut Fitriani (2014 ). Hasil aktivasi setelah 7 hari digunakan untuk memfermentasi limbah tahu dengan perbandingan 1:5 (1 liter EM4 aktif dan 5 liter limbah tahu); 1: 10 dan 1: 20 menurut Jasmiati dkk (2010) untuk mendapatkan ratio yang sesuai berdasarkan parameter dan untuk mendapatkan bioflok. Hasil pengukuran parameter ini kemudian dibandingkan dengan standar baku mutu limbah menurut Permen LH RI nomor 5 Tahun 2014 tentang baku mutu air limbah tahu. Gambar 2 menunjukkan aktivasi EM4 dan hasil bioflok yang terbentuk pada proses optimasi 1: 5; sedangkan tabel 1 dan tabel 2 menunjukkan hasil perbandingan tiap parameter pada ketiga jenis ratio limbah dan EM4 serta optimasi EM4.
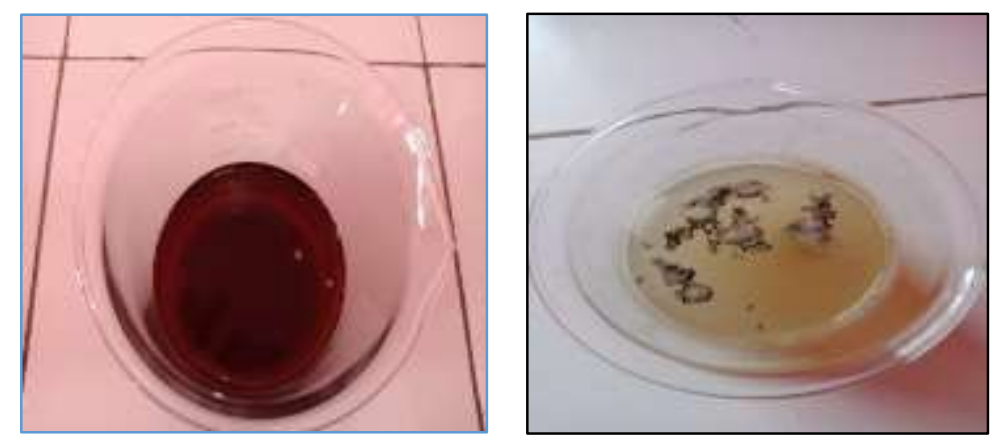

Gambar 2. Aktivasi Dan Optimasi EM4 Dengan Terbentuknya Bioflok

Tabel 1. Pengamatan parameter suhu dan $\mathrm{pH}$ pada tahap optimasi 


\begin{tabular}{|c|c|c|c|c|c|c|}
\hline \multicolumn{6}{|c|}{ Optimasi } & \multirow{2}{*}{$\begin{array}{c}\text { Standar* } \\
\text { baku } \\
\text { suhu: }\end{array}$} \\
\hline $\mathrm{Ha}$ & Paramete & Kontr & $1: 5$ & $1: 10$ & $1: 20$ & \\
\hline \multirow[t]{4}{*}{1} & Suhu & $220^{\circ} \mathrm{C}$ & $26^{0} \mathrm{C}$ & $27^{0} \mathrm{C}$ & $27^{0} \mathrm{C}$ & $26^{0} \mathrm{C}-28^{0} \mathrm{C}$ \\
\hline & $\mathrm{pH}$ & 4,38 & 7 & 6,7 & 64 & \\
\hline & Suhu & $\ldots \ldots$ & $27^{0} \mathrm{C}$ & $28^{0} \mathrm{C}$ & $28^{0} \mathrm{C}$ & \\
\hline & $\mathrm{pH}$ & $\ldots \ldots$ & 7,2 & 8,5 & 8,4 & pH: 6-9 \\
\hline \multirow[t]{2}{*}{7} & Suhu & $\ldots \ldots$ & $27^{0} \mathrm{C}$ & $28^{0} \mathrm{C}$ & $28^{0} \mathrm{C}$ & \\
\hline & $\mathrm{pH}$ & ...... & 7,6 & 8,4 & 9,1 & \\
\hline
\end{tabular}

Tabel 2 Hasil uji BOD, COD dan TSS pada tiap perlakuan

\begin{tabular}{lllll}
\hline Optimasi & Parameter & Hasil & Satuan & Baku mutu* \\
\hline Kontrol & BOD & 440,25 & $\mathrm{mg} / \mathrm{L}$ & $150 \mathrm{mg} / \mathrm{L}$ \\
& COD & 7103,88 & $\mathrm{mg} / \mathrm{L}$ & $300 \mathrm{mg} / \mathrm{L}$ \\
& TSS & 123 & $\mathrm{mg} / \mathrm{L}$ & $200 \mathrm{mg} / \mathrm{L}$ \\
\hline $1: 5$ & BOD & 412,12 & $\mathrm{mg} / \mathrm{L}$ & $150 \mathrm{mg} / \mathrm{L}$ \\
& COD & 913 & $\mathrm{mg} / \mathrm{L}$ & $300 \mathrm{mg} / \mathrm{L}$ \\
& TSS & 200 & $\mathrm{mg} / \mathrm{L}$ & $200 \mathrm{mg} / \mathrm{L}$ \\
\hline $1: 10$ & BOD & 510,1 & $\mathrm{mg} / \mathrm{L}$ & $150 \mathrm{mg} / \mathrm{L}$ \\
& COD & 1000,1 & $\mathrm{mg} / \mathrm{L}$ & $300 \mathrm{mg} / \mathrm{L}$ \\
& TSS & 100,2 & $\mathrm{mg} / \mathrm{L}$ & $200 \mathrm{mg} / \mathrm{L}$ \\
\hline $1: 20$ & BOD & 520,3 & $\mathrm{mg} / \mathrm{L}$ & $150 \mathrm{mg} / \mathrm{L}$ \\
& COD & 1200,31 & $\mathrm{mg} / \mathrm{L}$ & $300 \mathrm{mg} / \mathrm{L}$ \\
& TSS & 79 & $\mathrm{mg} / \mathrm{L}$ & $200 \mathrm{mg} / \mathrm{L}$ \\
\hline
\end{tabular}

Keterangan * Standar baku mutu limbah cair tahu sesuai dengan Permen LH No 5 Tahun 2014

Pada tahap optimasi ratio atau takaran EM4 dan limbah, diketahui bahwa ratio yang optimal untuk pengolahan limbah cair tahu menggunakan EM4 adalah 1 : 5 (1 liter EM4 aktif dan 5 liter limbah tahu) karena pada ratio ini semua parameter kualitas air limbah tahu (fisik maupun kimia-biologi) paling mendekati dengan nilai standar baku mutu limbah menurut Permen LH No.5 tahun 2014. Dan jika dilihat pada kadar BOD dan COD yang mengalami penurunan jika dibandingkan dengan ratio 1 :10 dan 1 : 20, maka dapat diasumsikan bahwa pada ratio $1: 5$ inilah merupakan ratio fermentasi atau pengolahan limbah yang paling sesuai. Menurut Jasmiyati dkk (2010), jika ratio limbah tahu dan EM4 tidak sesuai atau jumlah limbah tahu lebih besar dari EM4 maka kemampuan mikroorganisme mendegradasi limbah organik berkurang karena jumlah mikroorganisme yang sedikit tidak mampu mendegradasi jumlah limbah tahu yang besar. Meskipun jumlah nutrisi berupa bahan organik cukup tinggi yang berasal dari limbah cair tahu, 
namun mikrooganisme tersebut mempunyai faktor pembatas karena kemampuan mendegradasi tidak sesuai dengan kondisi lingkungan. Hal inilah yang menyebabkan kadar BOD pada kadar 1 : 10 dan 1:20 mengalami peningkatan karena jumlah oksigen yang dibutuhkan oleh mikroorganisme untuk mendegradasi bahan organik lebih tinggi pada kedua kadar tersebut. Kadar COD pada ratio 1 : 5 juga merupakan kadar yang paling rendah. Hal ini dapat diartikan bahwa mikroorganisme (EM4) bekerja dengan optimal untuk mendegradasi limbah dengan cepat. Mikroorganisme dalam limbah terus menerus melakukan proses metabolisme sepanjang kebutuhan energinya terpenuhi dan akan menghasilkan senyawa-senyawa yang dapat memberikan dampak terhadap turunnya nilai COD (Fardiaz, 1992).

Pada pengamatan parameter pertumbuhan tanaman diketahui bahwa terdapat perbedaan laju pertumbuhan baik pada perlakuan kontrol A1 maupun pada perlakuan A2 dan A3 seperti tampak pada tabel 3. Laju pertumbuhan tanaman selada paling optimal adalah pada perlakuan kontrol atau tanaman yang diberikan nutrisi hidroponik AB mix. Hasil uji lanjutan DMRT juga menunjukkan bahwa perlakuan A1 berbeda nyata dengan 2 perlakuan lainnya. Menurut Zary dkk (2018), dalam nutrisi AB mix terkandung unsur hara lengkap baik unsur hara makro maupun mikro yang dibutuhkan oleh tanaman. Menurut Resh (2004), larutan hara standar dalam sistem hidroponik adalah larutan AB mix yang terdiri dari stok A (berisi larutan hara A) mengandung $\mathrm{KNO}$, $\mathrm{Ca}(\mathrm{NO} 3) 2$, NH4NO3 dan FeEDTA, stok B (berisi larutan hara stok B) mengandung KNO3, K2SO4, KH2PO4, MgSO4, MnSO4, CuSO4, ZnEDTA, H3BO3 dan NH4-M0O4 dan asam dengan jumlah 15-20\% dari total larutan stok A dan B. 
Tabel 3 Perbandingan pertumbuhan tanaman selada Lactuna sativa $L$ pada tiap perlakuan

\begin{tabular}{|c|c|c|c|c|c|c|}
\hline $\begin{array}{l}\text { Perlakuan } \\
*\end{array}$ & $\begin{array}{l}\text { Hari } \\
\text { ke }\end{array}$ & $\begin{array}{l}\text { Tinggi } \\
\text { tanaman }\end{array}$ & $\begin{array}{l}\text { Jumlah } \\
\text { daun }\end{array}$ & $\begin{array}{l}\text { Panjang } \\
\text { tajuk }\end{array}$ & $\begin{array}{l}\text { Panjang } \\
\text { akar }\end{array}$ & $\begin{array}{l}\text { Biomassa } \\
\text { tanaman }\end{array}$ \\
\hline \multirow[t]{4}{*}{ A1 } & 1 & $2,14 \pm 0,13 \mathrm{a}$ & $4,1 \pm 0,31 \mathrm{a}$ & $2,48 \pm 0,1 \mathrm{a}$ & $1,02 \pm 0,06 \mathrm{a}$ & \multirow{4}{*}{$\begin{array}{r}2,04 \pm 0,08 a \\
5,82 \pm 0,09 \mathrm{ab} \\
12,04 \pm 0,17 \mathrm{c} \\
20,96 \pm-, 48 \mathrm{~d}\end{array}$} \\
\hline & 7 & $3,16 \pm 0,16 a$ & $5,9 \pm 0,56 a$ & $3,17 \pm 0,16 a$ & $2,05 \pm 0,08 \mathrm{a}$ & \\
\hline & 14 & $7,11 \pm 0,18 b$ & $8,8 \pm 0,42 \mathrm{ab}$ & $5,57 \pm 0,09 \mathrm{ab}$ & $4,87 \pm 0,17 b$ & \\
\hline & 28 & $15,14 \pm 0,24 \mathrm{c}$ & $11,7 \pm 0,48 \mathrm{c}$ & $11,51 \pm 0,15 \mathrm{c}$ & $7,63 \pm 0,19 b c$ & \\
\hline \multirow[t]{4}{*}{ A2 } & 1 & $1,6 \pm 0,14 \mathrm{a}$ & $4,1 \pm 0,31 \mathrm{a}$ & $1,98 \pm 0,25 a$ & $1,03 \pm 0,09 a$ & \multirow{4}{*}{$\begin{array}{r}2,04 \pm 0,12 \mathrm{a} \\
4,82 \pm 0,11 \mathrm{a} \\
8,8 \pm 0,36 \mathrm{ab} \\
16,86 \pm 1,59 \mathrm{~cd} \\
\end{array}$} \\
\hline & 7 & $2,91 \pm 0,15 \mathrm{a}$ & $5,2 \pm 0,42 \mathrm{a}$ & $2,99 \pm 0,19 a$ & $1,83 \pm 0,09 a$ & \\
\hline & 14 & $5,71 \pm 0,13 b$ & $7,5 \pm 0,52 \mathrm{ab}$ & $4,49 \pm 0,22 \mathrm{ab}$ & $4,02 \pm 0,13 \mathrm{ab}$ & \\
\hline & 28 & $11,17 \pm 0,32 \mathrm{c}$ & $9,8 \pm 0,63 b c$ & $10,43 \pm 0,49 \mathrm{c}$ & $5,8 \pm 0,16 \mathrm{c}$ & \\
\hline \multirow[t]{4}{*}{ A3 } & 1 & $1,65 \pm 0,15 \mathrm{a}$ & $4,1 \pm 0,31 \mathrm{a}$ & $1,74 \pm 0,15 \mathrm{a}$ & $1,24 \pm 0,11 \mathrm{a}$ & $2,03 \pm 0,08 \mathrm{a}$ \\
\hline & 7 & $3,31 \pm 0,38 \mathrm{a}$ & $5,3 \pm 0,48 \mathrm{a}$ & $2,34 \pm 0,18 \mathrm{a}$ & $2,32 \pm 0,18 \mathrm{a}$ & $5,93 \pm 0,42 \mathrm{ab}$ \\
\hline & 14 & $6,36 \pm 0,25 \mathrm{ab}$ & $7,9 \pm 0,31 \mathrm{ab}$ & $5,07 \pm 0,14 \mathrm{ab}$ & $4,8 \pm 0,14 b$ & $10,64 \pm 0,22 \mathrm{c}$ \\
\hline & 28 & $11,76 \pm 0,28 \mathrm{c}$ & $10,3 \pm 0,48 c$ & $11,15 \pm 0,43 c$ & $6,15 \pm 0,21 c$ & $17,54 \pm 1,2 \mathrm{~cd}$ \\
\hline
\end{tabular}

Keterangan : Huruf yang berbeda menunjukan beda nyata pada uji lanjut Duncan pada taraf 95\%

Kelengkapan nutrisi juga sangat berpengaruh pada konduktivitas listrik. Jumlah nutrisi yang mencukupi dan mudah diserap oleh tumbuhan akan merangsang pertumbuhan tanaman secara lebih cepat. Menurut Putra (2017), nutrisi dalam bentuk ion - ion dan mineral yang dibutuhkan tanaman dapat diketahui dari nilai EC dan TDS, karena nilai EC dapat menggambarkan konsentrasi ion dalam larutan yang dapat diserap oleh tanaman. Semakin pekat larutan umumnya semakin tinggi konsentrasi zat terlarut atau TDS-nya dan semakin tinggi nilai konduktivitas listriknya. Semakin pekat larutan nutrisi menyebabkan tanaman tidak mampu menyerap unsur hara dengan optimal. Konsentrasi EC dalam larutan mempengaruhi metabolisme tanaman, yaitu dalam hal kecepatan fotosintesis, aktivitas enzim dan potensi penyerapan ion-ion oleh akar (Subandi, 2015). Hasil pada penelitian ini menunjukkan bahwa nilai EC tertinggi terdapat pada perlakuan A2. Kepekatan limbah tahu dapat menyebabkan nilai EC yang tinggi sehingga tanaman kurang mampu menyerap nutrisi yang berakibat pada rendahnya metabolisme dan fotosintesis tanaman, sehingga pertumbuhan tanaman menjadi tidak optimal.

Pada tanaman yang diberikan perlakuan nutrisi dengan tanaman Pistia (A3) meskipun mempunyai nilai EC lebih rendah daripada A2 namun mempunyai pertumbuhan yang lebih tinggi daripada tanaman A2. Hasil uji lanjutan DMRT juga menunjukkan antar kedua perlakuan A2 dan A3 menunjukkan beda nyata pada hampir 
semua parameter pertumbuhan khususnya pada hari ke -28 . Hal ini terjadi diduga karena perlakuan tanaman Pistia mampu menyerap bahan organik yang terdapat pada limbah tahu sehingga berpengaruh pada nilai EC pada A3. Menurut Gregori (2006), pada akar kayu apu terdapat bakteri rhizosfer yang berperan dalam menyerap dan memecah senyawa organik pada limbah secara aerob sehingga dapat menurunkan kepekatan larutan sehingga menurunkan nilai EC.

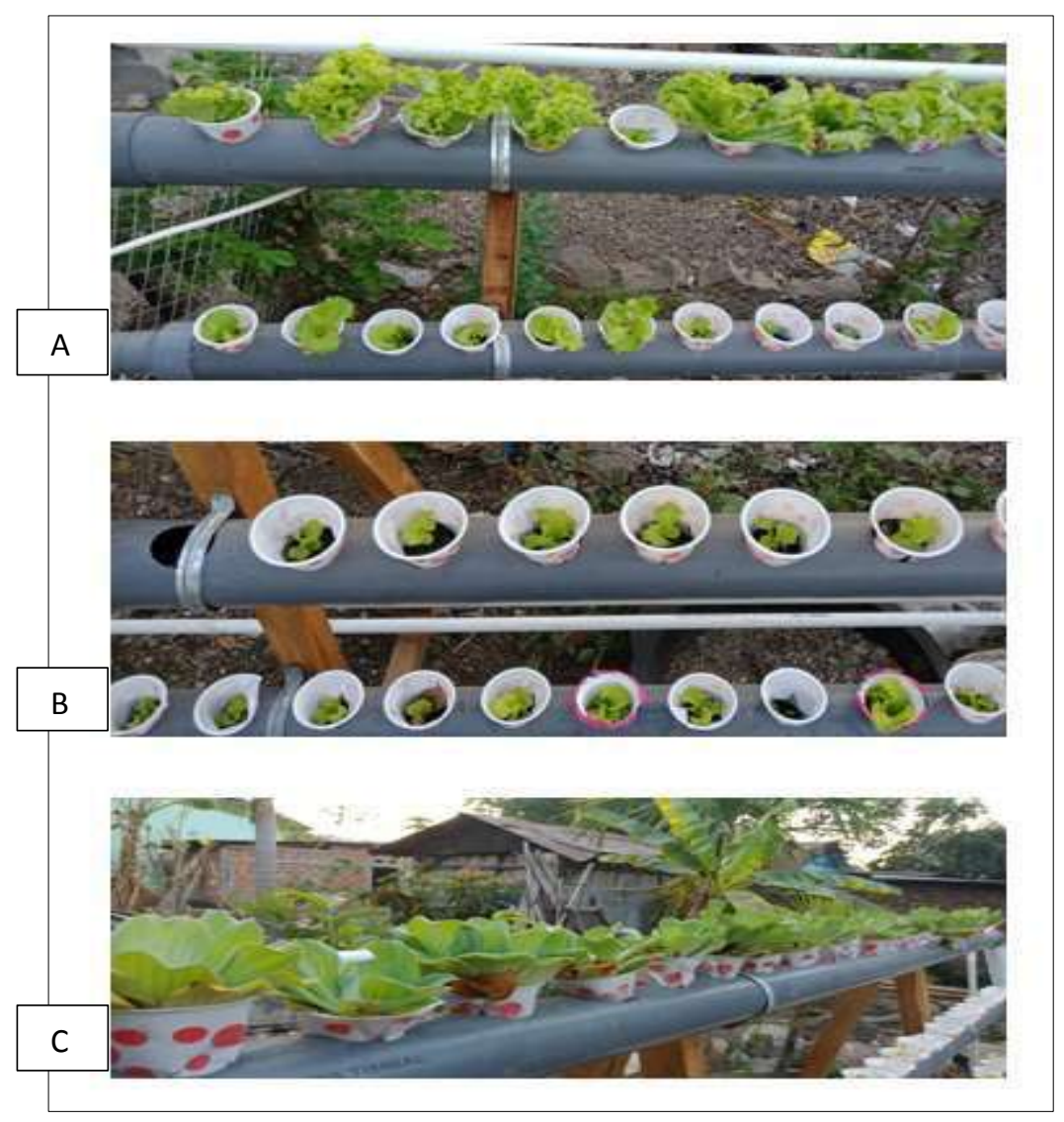

Gambar 3. Hasil pertumbuhan tanaman selada darat (Lactuna sativa $L$ ) pada 3 (tiga) perlakuan. A.Perlakuan menggunakan nutrisi ABmix atau A1.B.Perlakuan menggunakan limbah tahu atau A2.C.Perlakuan menggunakan limbah tahu dan tanaman kayu apu Pistia stratiotes L atau A3

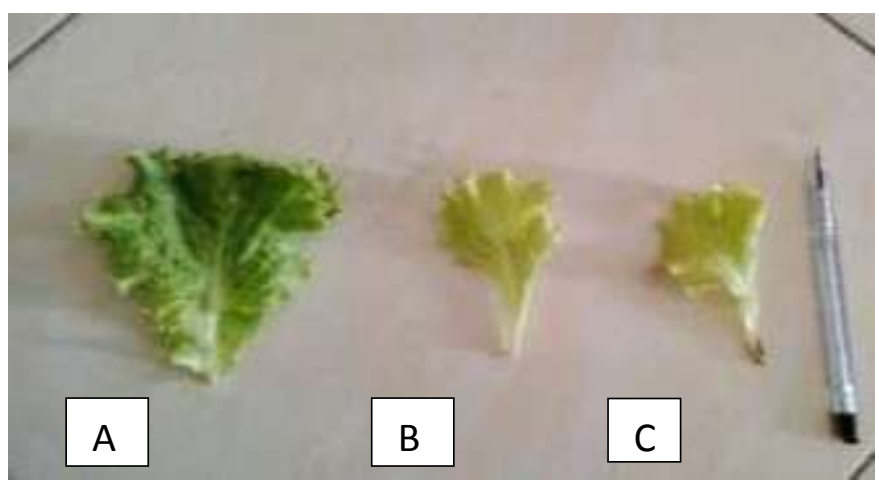




\section{Gambar 4. Pertumbuhan daun tanaman selada darat (Lactuna sativa L) pada 3 (tiga) perlakuan A.Perlakuan A1.B.Perlakuan A2.C.Perlakuan A3}

Uji lanjutan yang dilakukan pada kadar BOD, COD dan TSS pada media hidroponik menunjukkan adanya prosentase penurunan yang cukup tinggi, yaitu sebesar $88,2 \%$ pada perlakuan A2 dan 90,4\% pada perlakuan A3. Penurunan yang tinggi diduga karena selama dalam media hidroponik dilakukan penambahan air bersih untuk mengontrol TDS dan EC agar konsentrasinya tetap terjaga. Selain itu, terjadi penambahan oksigen atau aerasi ketika terjadi perputaran nutrisi. Menurut Jasmiati dkk (2010), kondisi aerasi akan menambahkan jumlah oksigen karena bakteri yang digunakan untuk mendegradasi limbah adalah bakteri aerob yang membutuhkan oksigen bebas. Kondisi ini akan menginisiasi interaksi efektif antara mikroorganisme (EM4) dan bahan organik pada limbah tahu. Penurunan nilai COD yang tidak sama besarnya dengan penurunan BOD diduga karena bahan-bahan stabil terhadap reaksi biologi dan mikroorganisme dapat ikut teroksidasi dalam uji COD (Fardiaz, 1992). Grafik 1 menunjukkan perbandingan kadar BOD, COD serta TSS pada tahap tiap perlakuan.

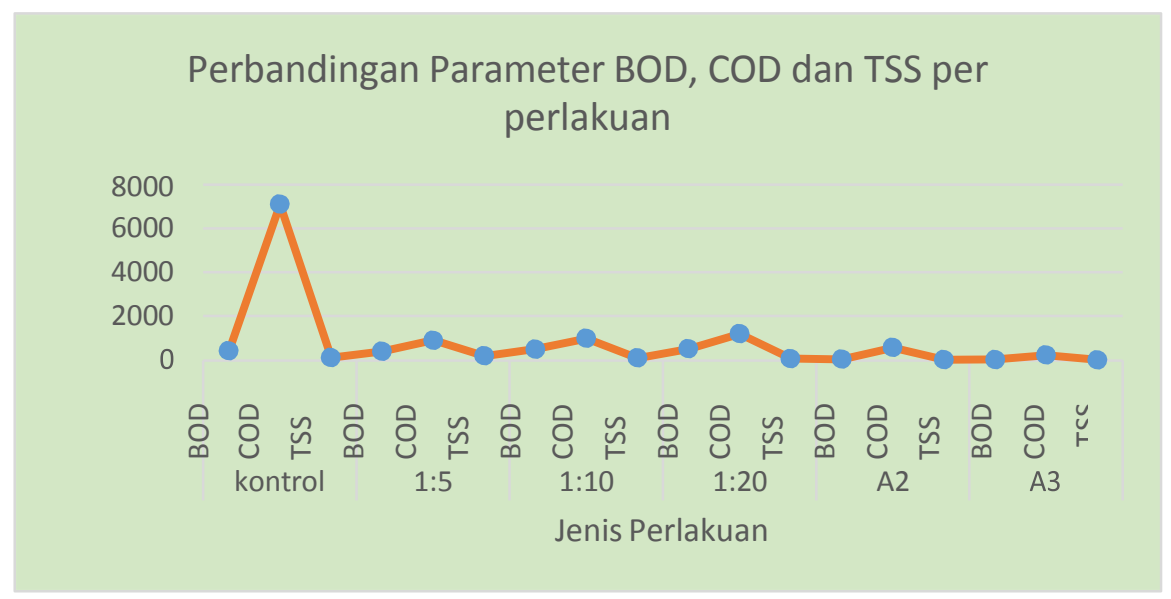

\section{Gambar 5 Perbandingan kadar BOD, COD dan TSS pada tiap perlakuan. Kontrol adalah limbah tahu tanpa penambahan EM4.}

Selain dapat mempengaruhi konduktivitas listrik pada limbah, kayu apu juga dapat mempengaruhi penurunan kadar BOD,COD dan TSS. Pada perlakuan A3 diketahui bahwa kadar BOD,COD dan TSS mengalami penurunan yang cukup signifikan, seperti tampak pada grafik 1. Penurunan BOD dapat disebabkan oleh menurunnya kandungan bahan organik dalam air limbah karena tanaman Pistia stratiotes L. mampu mensuplai oksigen ke dalam limbah dan menyerap hasil dekomposisi bahan organic (Fachrurozi dkk, _). COD atau Chemical Oxygen Demand adalah nilai yang menunjukkan jumlah oksigen untuk 
mengoksidasi senyawa organik yang terdapat pada 1 liter larutan yang dinyatakan dalam satuan mg/l. Menurut Mulia (2005), senyawa organik dalam COD meliputi senyawa yang dapat diolah secara biologis (biodegradable) dan tidak dapat diolah secara biologis (nonbiodegradable). Menurut Rahadian dkk (2017) proses penyisihan COD pada kayu apu terjadi karena proses fotosintesis menghasilkan oksigen yang kemudian dilepas ke dalam air/limbah yang dapat mengoksidasi senyawa organik yang dilakukan oleh kayu apu. Penurunan BOD,COD dan TSS yang diikuti dengan peningkatan pertumbuhan tanaman selada pada perlakuan A3 mengindikasikan bahwa larutan fermentasi limbah tahu dan EM4 pada ratio $1: 5$ dapat digunakan sebagai alternatif nutrisi pada media hidroponik meskipun pertumbuhannya masih dibawah pertumbuhan menggunakan nutrisi ABmix.

\section{KESIMPULAN}

Pengolahan limbah cair tahu menggunakan EM4 pada ratio 1:5 mampu mengurangi parameter kualitas limbah cair ( $\mathrm{pH}$, kekerihan,suhu, BOD,COD dan TSS) meskipun masih diatas standar baku mutu air limbah cair tahu. Limbah cair tahu dan EM4 pada ratio 1 : 5 dapat digunakan sebagai alternatif nutrisi limbah cair tahu meskipun dengan parameter pertumbuhan yang belum optimal. Sistem hidroponik dengan memanfaatkan kayu apu dapat digunakan sebagai alternatif pertumbuhan. Penelitian lanjutan diperlukan untuk mengidentifikasi penggunaan tanaman selada untuk dikonsumi

\section{UCAPAN TERIMAKASIH}

Peneliti mengucapkan terimakasih kepada LPPM Unimor yang telah mendanai penelitian ini. Dan semua pihak yang telah mendukung penelitian ini.

\section{DAFTAR PUSTAKA}

Andika Priyono . 2007. Pengaruh Pistia stratiotesL. Dalam Peningkatan Kualitas Air. Skripsi. IPB. Bogor

Arif Rizki. 2013. Analisis Pengelolaan Limbah Tahudi Kecamatan Adiwerna Tegal.Skripsi. Universitas Diponegoro

Aris Sutrisno, Evie Ratnasari, Herlina Fitrihidajati. 2014. Fermentasi Limbah Cair Tahu Menggunakan EM4 Sebagai Alternatif Nutrisi Hidroponik dan Aplikasinya pada Sawi Hijau (Brassica juncea var. Tosakan). Jurnal Lentera Bio. 4 (1) 
Astuti, A. D, Wicaksono, W., dan Nurwini, A. R. 2007. Pengolahan Air Limbah Tahu Menggunakan Bioreaktor Anaerob-Aerob Bermedia Karbon Aktif dengan Variasi Waktu Tinggal. Dalam R. Agung Tuhu., H. S. Winata. 2010 Jurnal Teknik Lingkungan Ilmiah Teknik Lingkungan. 2 (2)

Badan Pusat Statistik (BPS). TTU dalam Angka. Kabupaten Timor Tengah Utara 2016

Chadirin, Y. 2007. Teknologi Greenhouse dan Hidroponik. Diktat Kuliah. Dep.Tek.Pertanian.IPB. Bogor.

Djuarnani, N, Kristian dan Budi S.S. 2005. Cara Cepat Membuat Kompos. Agromedia Pustaka. Jakarta.

Farid. 2008. Pengaruh Perubahan Kuat Arus Listrik Terhadap Penyisihan Bahan Organik Limbah Cair Industri Tahu Dengan Proses Plasma, Jurusan Teknik Lingkungan FTSP UPN "Veteran” Jawa Timur, Surabaya

Finsha Alfani Putra. 2017. Rancang Bangun Sistem Kendali Electrical Conductivity (Ec) Otomatis Limbah Cair Tahu Sebagai Larutan Nutrisi Hidroponik Berbasis Mikrokontroler, Teknik Pertanian.Fakultas Pertanian Universitas Lampung

Herlambang. 2002. Teknologi Pengolahan Limbah Cair Industri Tahu. Jakarta: Pusat Pengkajian dan Penerapan Teknologi Lingkungan dan Badan Pengendalian DampakLingkungan Daerah Samarinda.

Hermansyah Mamonto. 2013. Uji Potensi Kayu Apu (Pistia stratiotes L) Dalam Penurunan Kadar Sianida (CN) Pada Limbah Cair Penambangan Emas. Skripsi. Program Studi

Kesehatan Masyarakat. Fakultas Ilmu-Ilmu Kesehatan dan Keolahragaan. Universitas Negeri Gorontalo

Jasmiati, Sofia A, Thamrin. 2010. Bioremediasi Limbah Cair Industri Tahu Menggunakan Efektif Mikroorganisme (EM-4). Journal of Environmental Science. 2010:2 (4).

Mohammad Istnaeny Hudha, Jimmy Muyassaroh. 2014. Studi penurunan cod dan tss limbah cair industri tahu menggunakan proses elektrokimia. Prosiding Seminar Nasional Kimia.

Nugraha, R. U. 2014. Sumber Hara Sebagai Pengganti AB mix pada Budidaya Sayuran Daun Secara Hidroponik. Skripsi. Departemen Agronomi Dan Holtikultura. Institut Pertanian Bogor

Nurhayati Hakim. Dasar-dasar Ilmu Tanah. 1986, Universitas Lampung: Lampung 
Rosliani dan Sumarni. 2005. Budidaya Tanaman Sayuran Dengan Sistem Hidroponik. Bandung : Balai Penelitian Tanaman Sayuran

Subhan dan Dimyati, 2002. Prospek Pengembangan Teknologi Hidroponik dan Produk Sayuran Bersih di Indonesia. Modul Pelatihan Aplikasi Teknologi Hidroponik untuk Pengembangan Agribisnis Perkotaan. Bogor, 28 Mei - 7 Juni 2002. Kerjasama CREATA-IPB dan Depdiknas

Suharjito. 2005. Efektifitas Pemberian Effective Microorganism Terhadap Penurunan BOD Pada Limbah Cair Tahu Di Desa Menguneng Kecamatan Warungasem Kabupaten Batang. Semarang:UniversitasDiponegoro.

Suryati Tuti, Budi Priyantoi. 2003. Eliminasi Logam Berat Kadmium Dalam Air Limbah Menggunakan Tanaman Air. Jurnal Teknologi Lingkungan-P3TLBPPT Vol. 4. No. 3

Tuhu Agung R, Hanry Sutan Winata. 2012. Pengolahan air limbah industri tahu dengan menggunakan teknologi plasma. Jurnal Ilmiah Teknik Lingkungan.02 (02)

Yusuf, Guntur. 2001. Proses bioremediaasi limbah rumah tangga dalam skala kecil dengan kemampuan tanaman air pada sistem simulasi. IPB 